\title{
NANOTECHNOLOGY AS A FACTOR IN THE DEVELOPMENT OF REGIONAL CLUSTERS
}

\author{
Sergey Vasilevich Kupriyanov* \\ Belgorod State Technological University named after V.G. Shukhov, Russia \\ Zhanna Nikolaevna Avilova \\ Belgorod State Technological University named after V.G. Shukhov, Russia \\ Elena Vladimirovna Kachyrova \\ Belgorod State Technological University named after V.G. Shukhov, Russia \\ Lyudmila Alekseevna Minaeva \\ Belgorod State Technological University named after V.G. Shukhov, Russia \\ Alexander Yakovlevich Arkatov \\ Belgorod State Technological University named after V.G. Shukhov, Russia
}

Work purpose: to reveal extent of influence of nanotechnologies on efficiency of use of available potential of innovative activity of the region and formation of regional clusters. Regions now endure process of radical restructuring of geographical, political and cultural subjects in subjects with a threefold spiral from business, science and the government which put forward new innovative initiatives. The regional threefold spiral grows from space of knowledge, consensus and innovations. Nanotechnology, becoming a priority branch of modern science, require ambiguous approach to their analysis and classification. In this context include the cluster as an adapter between the fundamental science and integrated developments. Formation of integrated technological solutions is the key advantage of the cluster; ensure the transfer of knowledge on new physical principles and the effects obtained in the laboratories of the academic institutes of the country in industrial production technology, as well as in technological know-how of instruments and instrumentation systems, a new class for various industries. Nanoindustry formation as new way of production of goods and services on a global scale was already shown as the tendency covering an increasing number of branches and spheres of economy, changing the economic and social relations of people.

Key Words: Nanotechnology, Clusters, Nanoindustry, Innovative development

\section{INTRODUCTION}

Formation of nanoindustry as the new method of production of goods and services on a global scale have emerged as a trend, covering an increasing number of industries and sectors of the economy, changing economic and social relationships of people [01]. Nanotechnology naturally become the basis for a new economic system at all levels of the global economic system, which leads to the formation of the interactions of individuals and enterprises, business and government, science and production. All this stimulates new way of life mankind [12].

One of the tools of nanotechnology research is cluster analysis, which is increasingly being applied in various studies. Cluster analysis is intended for splitting of a collection of objects into homogeneous groups (clusters) [03].
Cluster analysis does not require any a priori assumptions about the dataset does not impose restrictions on the presentation of researched objects, allows to analyze the performance of various data types. Cluster analysis allows one to reduce the dimension of the data, to make it visible. The use of cluster analysis in the study of nanotechnology will be useful for the development of national nanoindustry taking into account plurality of interests of its participants: the state in strategic planning; corporations-contractors in order of their position on the external market; participants NNN - keeping purposes of effective business in the field of high technologies [10]. 


\section{THE METHODOLOGY}

Cluster analysis allows one to reduce the dimension of the data, to make it visible. Cluster analysis was developed in the first half of the $20^{\text {th }}$ century. The idea of "structural classification was put forward by the Polish anthropologist $\mathrm{K}$. Chekanovskiy in 1913 as a first step in this direction [07]. This method was a typical example of pre-computer data processing technologies. But it contained an anchor idea of cluster analysis is a selection of compact groups of objects and important means of this selection procedure - the underlying later algorithms diagonalizable matrix of communication. In 1925, our compatriot hydrobiologist P.V. Terentyev was developed the method of correlation of pleiades" [06]. The correlation within complexes signs in the absence of connection between characteristics of different complexes P.V .Terentyev called "correlation pleiades". Although this method is aimed at selecting groups of closely correlating signs that he had been used for the classification of objects. The idea of the approach is in fact the basis for numerous threshold algorithms, algorithms on graphs, developed in subsequent years.

\section{DELIVERABLES}

Having studied the world experience of cluster analysis to date, there are two types of cluster development, namely: North-American and Asian types [04].

Considers the international experience in the field of cluster analysis confirms that the modern production of high technologies can be used for processes of integration, the formation of clusters. Foreign experience of development and implementation of regional clusters involves the following tasks: selection of the target segment, promising consumer demand, public funding priority areas, institutional support, marketing programs, copyright protection, improvement of research and experimental-design works.

Identified the following specific features taken into account when carrying out a cluster analysis of the market of nanotechnology [02]:

First, the availability of new, unknown and highly value (enjoying buoyant demand in the long 1015 years term related to the implementation of the results of fundamental research) in the short and long term prospective properties.

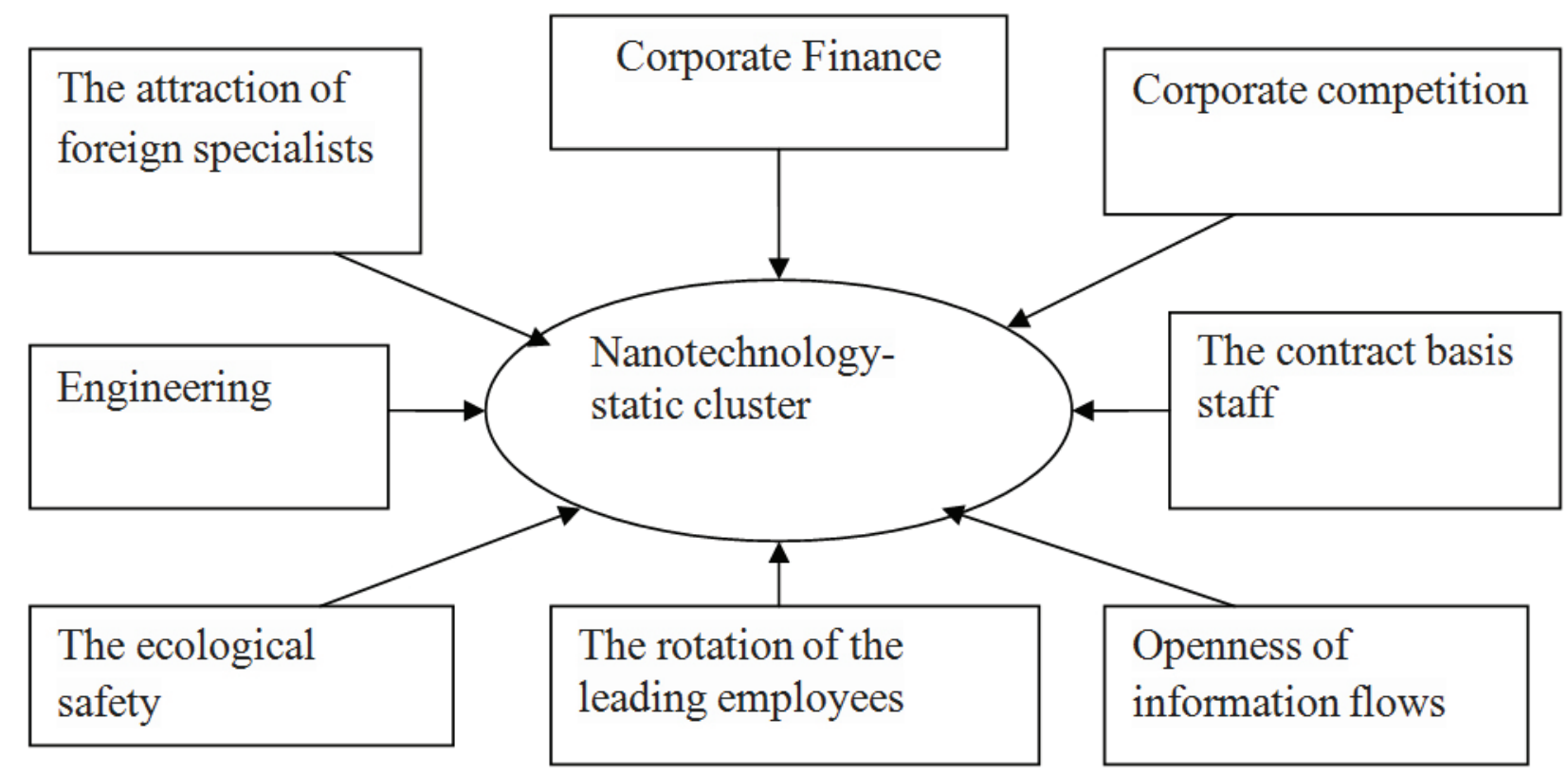

Figure 1: Main features of the model of the nanocluster North American type

Secondly, nanotechnology should reflect longterm multiplier effect.

Thirdly, the implementation of nanoproducts developers and manufacturers must extract intellectual rent, able to provide the complete innovation cycle necessary funds for fundamental research and the production on their basis of new nanoproducts.

Fourth, for the market of nanoproducts characterized by a high degree of monopolization and specific pricing.

Fifthly, the production of nanoproducts involves innovation (with new professional knowledge) of the experts. 
G.L. Azoev the following definition: nanotechnology cluster is a production organization system in interdisciplinary scientific field allows you to give impetus to the development of radically nano-new goods and services that can structurally change the region's economy, increase its competitiveness and quality of life of the population [09].

Summarizing the above, we suggested to the author's definition of the nanotechnology cluster. Regional nanotechnology cluster is concentrated group of interrelated elements: research institutes; universities, technoparks and infrastructure, mutually reinforcing and strengthening the competitive advantages of individual companies and nanocluster in general. For the development of the nanotechnology cluster Belgorod region used two models of the formation of clusters:

1. The North American model type:
Figure 1 - Main features of the model of the nanocluster North American type

Peculiarities of nano-model of the North American type include:

1. Corporate direction;

2. The participation of foreign experts;

3. The availability of information to third parties;

4. Sale of high technologies;

5. Competition on the labour market for skilled personnel;

6. Ensuring environmental safety and the maintenance of ecological balance.

North American type nano-oriented international cooperation, envisaging the involvement of foreign personnel and technology; sales of not only the end of high-tech products but also high technologies.

2. Model Asian type:

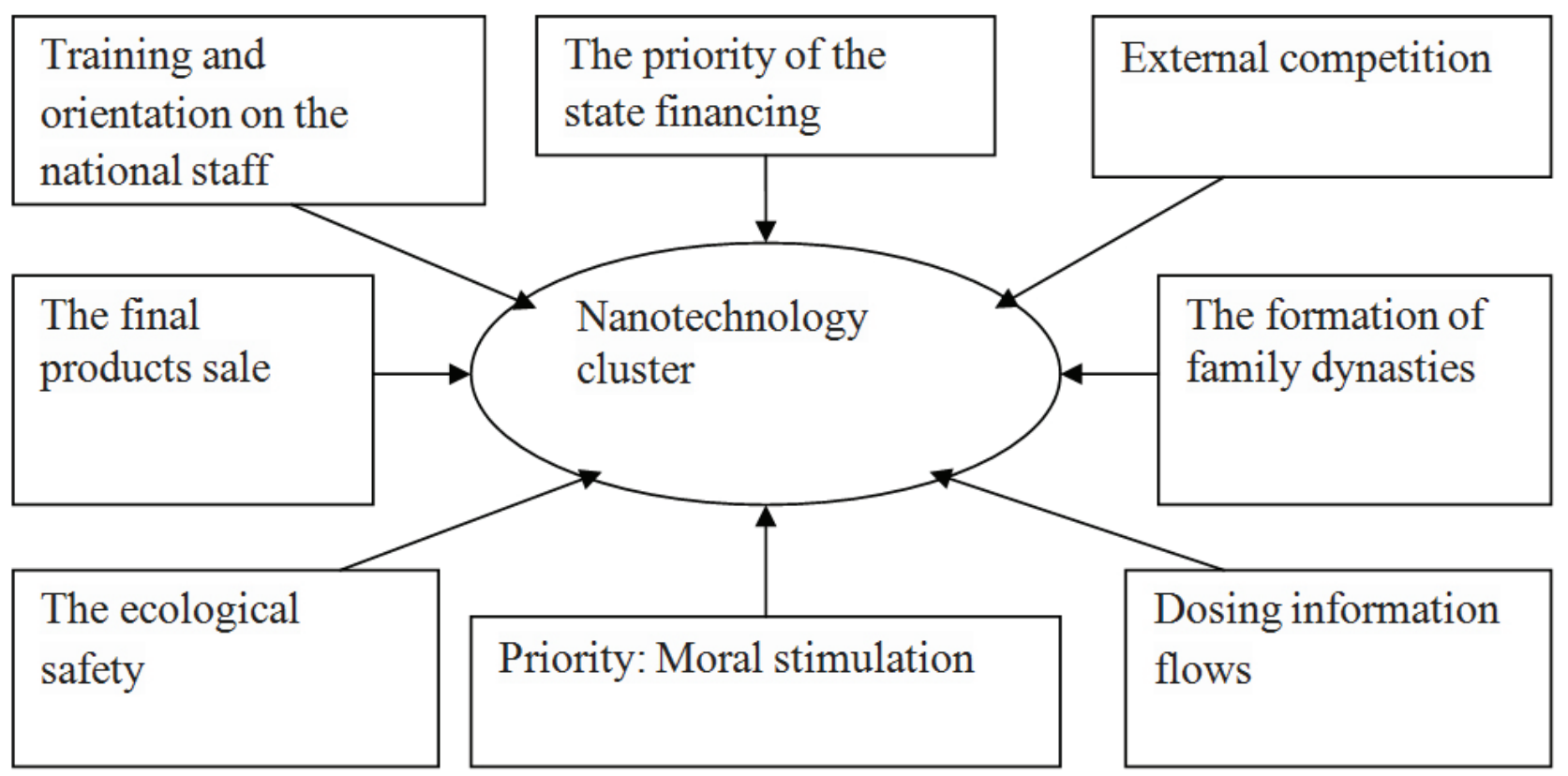

Figure 2: Main features of the model of the nanocluster Asian women

Peculiarities of nano-model Asian women include:

1. State direction;

2. Formation of own specialists;

3. Restricted information third-party organizations.

4. The sale to end-tech products;

5. The lack of domestic competition in the labor market for more qualified workers;

6. Ensuring environmental safety and the maintenance of ecological balance.
Asian type of the nanocluster focused on the domestic economy, involves the formation of its own personnel and technology; sale only endtech products. Hence, for Russia the greatest extent applicable exactly the Asian model of organization of nanoclusters. In accordance with this model nanoclusters developed through private and state regulation of economic processes. At the same time, Russia has a number of features of development of nanoproducts, which will be considered later. A schematic representation of the developed regional nanocluster Figure 3. 


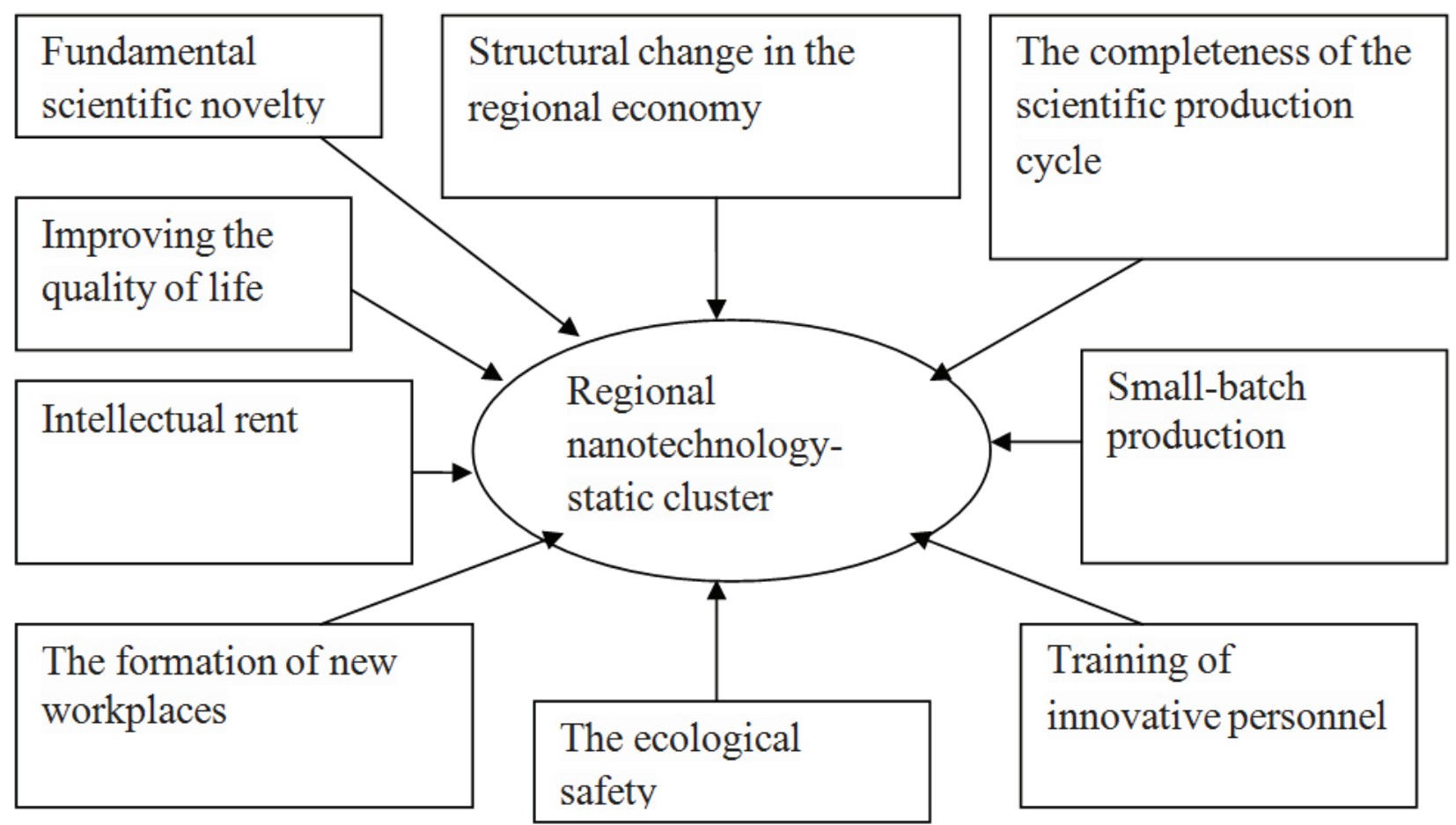

Figure 3: Content of the category of regional nanocluster

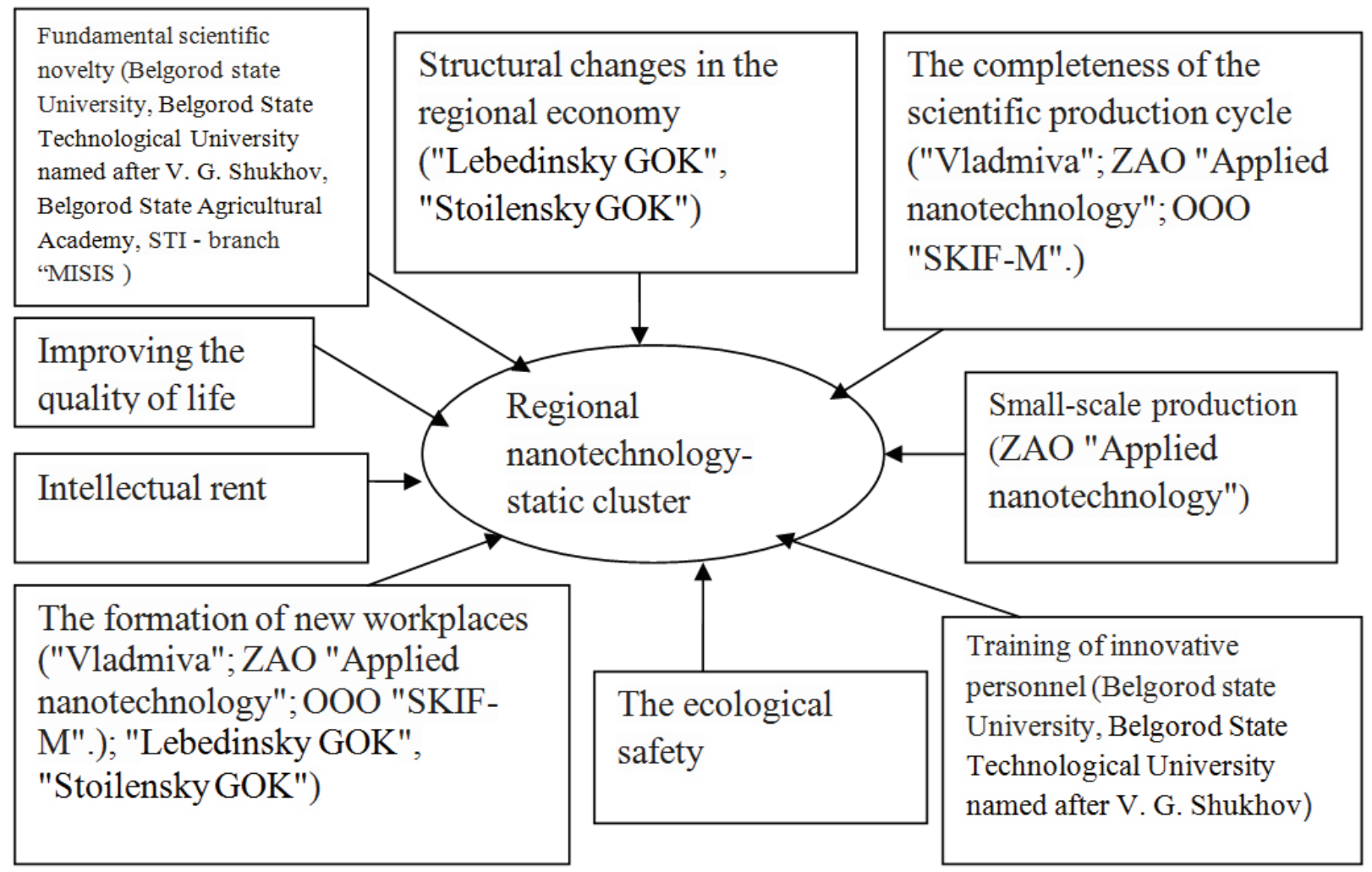

Figure 4: Nanotechnology cluster Belgorod region

Regional nanotechnology cluster is a production organization system in interdisciplinary scientific field allows you to give impetus to the development of radically nano-new goods and services that can structurally change the region's economy, increase its competitiveness and quality of life of the population. The primary aim of development of regional nanoclusters is a material provision of the high level and quality of life [09]. At formation of the nanotechnology cluster Belgorod region, consider the following: 
1) In a segment of marketing researches it is advisable to use the existing intra-regional division of intellectual and innovative work. Specialization areas mining industry is represented by "Lebedinsky GOK", "Stoilensky GOK".

2) Secondly, manufacture of pharmaceutical products for humans and animals (ZAO "Applied nanotechnology", Belgorod State Agricultural Academy and others)

3) Thirdly developed agricultural sector, is provided "Belgrankorm", ZAO "Prioskolye".

4) Fourth, innovation technologies in medicine and health care, physical and intellectual base ("Vladmiva" and others).

5) Fifthly, the development of new technologies in road construction and civil engineering, material base GBK-1 and OAO "Energomash", as well as developments $\mathrm{OOO}$ "SKIF-M".

6) Sixth, overcoming the shortage of scientific personnel in the industry nanobiotechnologies ("Belgorod state University, Belgorod State Technological University named after V. G. Shukhov, Belgorod State Agricultural Academy, STI - branch "MISIS").

Proposed nanocluster Belgorod region will have the following appearance:

The primary aim of development of regional nanoclusters is a material provision of a high level and quality of life of the population.(Figure 4)

The achievement of this aim is possible only under the decision of following problems:

1. The sustainable development of regional economies in the structure of Russian space.

2. Enhancing balance and comprehensiveness of the regional economy.

3. Organization of output of products represented in the region on the Russian market.

4. Forming a self-sufficient surplus to regional budgets in [10].

\section{CONCLUSION}

The proposed nanotechnology cluster is defined as unique technical innovation and scientificeducational system oriented to accelerate the application of modern technologies, introduction into production of results of scientific and technical activity [11].
As a result of formation and development of the nanocluster happens creation and increase jobs. In the fulfillment of the tasks on formation on the territory of Belgorod region of the elements of the national nanotechnological network, according to the Strategy of development of the Belgorod region to had, by 2015, the expected increase of production volumes of nanotechnology products to 20.3 billion rubles, the share of consumption of innovation, including nanotechnology, products within the scope of public procurement - to $3.5 \%$ [12].

\section{ACKNOWLEDGEMENTS}

The article was published with the financial support from Ministry of Education and Science of the Russian Federation within the framework of state assignment to the project \#26.1511.2014K "Theory and methodology of managing innovational and investment processes in small business enterprises."

\section{REFERENCES}

1) Avilova, Z.N. (2012): The development of nanotechnologies of Belgorod region: trends and prospects, Social and humanitarian knowledge, No 8, pp. 125-132.

2) Asoev, G.L. (2011): The market of nano: from nanotechnology - to the nano-products, $M$ : BINOM. Knowledge laboratory.

3) Association of European Science and Technology Transfer Professional. http://www. astp.net, retrieved on September 7th, 2014.

4) Avilova, Z.N. (2013): Formation of the innovative environment of the region: from fundamental science to complex development, Belgorod: publishing house BGTU.

5) Buhonova, S.M., Doroshenko, Y.A., Tumina, T.A., Konoplyanko, O. I. (2007): The cooperation of enterprises in the production of innovative high-tech products in a competitive market, Economic analysis: theory and practice, No 3, pp. 2-5.

6) Cluster development in conditions of globalization: experience of foreign countries, http://www.kisi.kz/img/docs/, retrieved on September 7th, 2014.

7) Haidukov, D.S. (2009): Use of cluster analysis in public administration. The philosophy of mathematics: actual problems, M: MAKS Press. 
1) Resolution of the government Belgorod region on 18.01.2010 N 9-PP (from January 17) "On approval of the long-term target program "Development nanoindustry of the Belgorod region in 2010 - 2014".

2) Romanovich, M.A., Rudychev, A.A., Romanovich, L.G. (2011): Venture capital investment in innovative enterprises abroad and in Russia, Bulletin of BSTU named after V.G. Shukhov, No 4, pp. 124-127.

3) Taranenko, S.B., Ivanov, K.V. (2011): National research centre "Kurchatov Institute", Russian nanotechnology, 2011, No 9-10.
4) Terentyev, P.V. (1960): Further development of the method of correlation Pleiades. Application of mathematical methods in biology, Leningrad: Publishing house of Leningrad state University.

5) The American Association of University Managers and Transfer of Technology. http://www. autm.net, retrieved on September $7^{\text {th }}, 2014$

Paper sent to revision: 05.11.2014.

Paper ready for publication: 12.12.2014. 